\title{
A review of published and unpublished findings from 20 long-term monitoring studies of eastern monarch butterflies: the population was never in danger, despite recent winter colony declines
}

\author{
Andrew K. Davis \\ Odum School of Ecology, University of Georgia, Athens GA 30602
}

\begin{abstract}
There are a large number of wildlife and insect species that are in trouble on this planet, and most believe that monarch butterflies in eastern North America are too, because of the well-publicized declines of their winter colonies in central Mexico in the last 25 years. A small number of studies over the last decade have cast doubt on this claim by showing declines are not evident at other stages of the annual cycle. To determine how extensive this pattern is, I conducted an exhaustive review of peerreviewed and grey literature on (eastern) monarch population censuses and studies, conducted across all seasons, and extracted data from these sources to evaluate how monarch abundance has or has not changed over time. I identified 20 collections of data that included butterfly club reports, compilations of citizen-science observations, migration roost censuses, long-term studies of isotopic signatures, and even museum records. These datasets range in duration from 15 years to over 100 years, and I endeavored to also update each with information from the most current years. I also reexamined the winter colony data after incorporating historical records of colony measurements dating back to 1976. This represents the most complete and up-to-date synthesis of information regarding this population. When I examined the long-term trajectory within each dataset a distinct pattern emerged. Modest declines are evident within the winter colonies (over the full 45 year dataset), and, within three censuses conducted during the spring recolonization. Meanwhile, 16 completely separate monitoring studies conducted during the summer and fall (and from varying locations) revealed either no trend at all or in fact an increase in abundance. While each of these long-term studies has inherent limitations, the fact that all 16 sources of data show the same pattern is undeniable. Moreover, this evidence is consistent with recently-conducted genetic work that shows a lack of decline. Collectively, these results indicate that despite diminishing winter colonies and spring migrations, monarchs in eastern North America are capable of rebounding fully each year, implying that milkweed is not limiting within their collective range. Moreover, there is no indication from these data that the summer population was ever truly diminished by changing agricultural practices in the Midwest that reduced milkweed in crop fields within that region. It is possible that the larger population is not as dependent on Midwestern agricultural milkweed as once thought, and/or that monarchs are adapting to increasingly human-altered landscapes. These results are timely and should bear on the upcoming USFWS decision on whether the
\end{abstract}


monarch requires federal protection in the United States. Importantly, they argue that despite losses of many insects globally, the eastern North American monarch population is not in the same situation.

Keywords: monarch butterflies, Danaus plexippus, population status, conservation, longterm studies, milkweed limitation

There is little doubt that the earth is changing from the activities of humans. For most of the world's biota, these changes are inflicting significant harm at a local and international level. A well-publicized example is the losses of many insect populations around the world, and many scientists believe this is one of the most dire conservation issues facing this planet (Basset and Lamarre 2019, Black 2019, Forister et al. 2019, Didham et al. 2020, Wagner 2020). Insects are indeed an integral part of the food chain in any functioning ecosystem, and moreover, some insects provide immense and direct benefits to human welfare, such as pollinators of our agricultural crops. However, a lesspublicized fact is that the broad-scale changes wrought by humans may not be detrimental to all insect species (Crossley et al. 2020, Halsch et al. 2020). In fact, certain species may be able to adapt to the new landscapes and human settlements, with little noticeable change to their overall populations. For example, in a recent analysis of butterfly censuses conducted over 20 years throughout the state of Ohio, USA, Wepprich et al. (2019) documented overall declines in 32 species, though 40 species showed no change, and 9 species increased. Thus, of the 81 butterfly species examined, 49 (60\%) could be characterized as having stable or growing populations in Ohio over the last two decades, according to these censuses. This fact was not reported in widespread media coverage of that study, where headlines read: "Butterfly death: Ohio butterflies are dying", and "Butterfly numbers fell by one third" (pers. obs.).

Arguably, few other insects in the world capture as much public and scientific attention as the iconic monarch butterfly, Danaus plexippus, of North America (Gustafsson et al. 2015). This charismatic species has a four-stage annual cycle that tracks changes in seasons (Table 1). In the summer, they have a broad breeding distribution over much of the United States and Canada, utilizing the one hundred+ different varieties of milkweed for oviposition. At the end of the summer, those monarchs east of the Rocky Mountains attempt a perilous (but spectacular) long-distance migration to specific mountaintop sites in Central Mexico, while those west of the Rockies have a shorter migration to sites along the California coastline. The adults remain until the end of the winter, when they make a return trip northward in the spring, laying eggs to recolonize the breeding range in the summer. Importantly, these winter colonies have been shrinking over the last two decades, in both Mexico (Brower et al. 2012b) and in California (Schultz et al. 2017). These declines have been the focal point for a virtual mountain of interest from journalists and everyday citizens, and are probably what has 
led to the monarch's status as a conservation icon (Gustafsson et al. 2015). Indeed, so much attention has been devoted to the winter colony declines (most attention is on the Mexico colonies), that the idea that the monarch itself is declining has become a dogmatic narrative. Add to this, the fact that a petition was submitted to the USFWS to consider placing the monarch on the endangered species list (Center for Biological Diversity 2014), and it becomes clear that the "monarchs are declining" narrative is a widespread perception, even among scientists and experts. In fact, in a recent collection of 34 articles published by leading scientists studying monarchs, 28 (82\%) of the articles re-stated this narrative at the outset of their article in some way (Diffendorfer et al. 2020). As of the time of this writing, a decision is still pending for the federal listing.

What has led to this narrative? Over the last decade, a variety of scientific studies have been published asserting that the eastern monarch population is in serious trouble, based solely on the declines in winter colony size in Mexico over the last 20+ years. These studies have included detailed statistical examination of correlates of this winter decline (Pleasants and Oberhauser 2013, Oberhauser et al. 2017, Thogmartin et al. 2017b, Stenoien et al. 2018), and each shows how the decline in winter colony size has occurred roughly over the same time period as the increase in use of herbicide-tolerant crops in the American Midwest, which was traditionally viewed as the core breeding area of the eastern population (Wassenaar and Hobson 1998). This change in agricultural practice has led to a dramatic decline in milkweed presence in farm fields. This correlative evidence has been used to support the "milkweed limitation hypothesis," which argues that the loss of milkweed in Midwestern agricultural fields is responsible for declines in recruitment within the summer months (Brower et al. 2012b, Pleasants and Oberhauser 2013, Pleasants 2017, Pleasants et al. 2017, Thogmartin et al. 2017b). The results of these studies are not in dispute. However, while the statistical analyses within these studies are not wrong per se, what is misplaced, is the myopic view of these winter colonies (and the colony size data) as the only source of information on the eastern monarch population. In fact, within these studies, and elsewhere, there appears to be a purposeful conflation of terminology such that these winter colonies are being synonymously labeled as "the population". In other words, these articles, either by design or accident, insinuate that what is happening at these colonies (a decline) is reflective of the entire monarch population elsewhere - i.e. the entire "population" is near collapse (Semmens et al. 2016).

Besides the winter colony data, there are actually many long-term monitoring projects ongoing in North America that track abundance of butterflies (including monarchs), or monarchs specifically, and over different seasons (Figure 1). 
Figure 1. Visual depiction of the monarch butterfly annual cycle in eastern North America, and the associated long-term datasets that were identified that track monarch abundance during those stages. Note that the datasets listed here do not include certain projects that investigated natal origins of wintering monarchs (Flockhart et al. 2017), or museum records of monarchs (Ries et al. 2019). Photo credits: Lincoln Brower and Michelle Good.

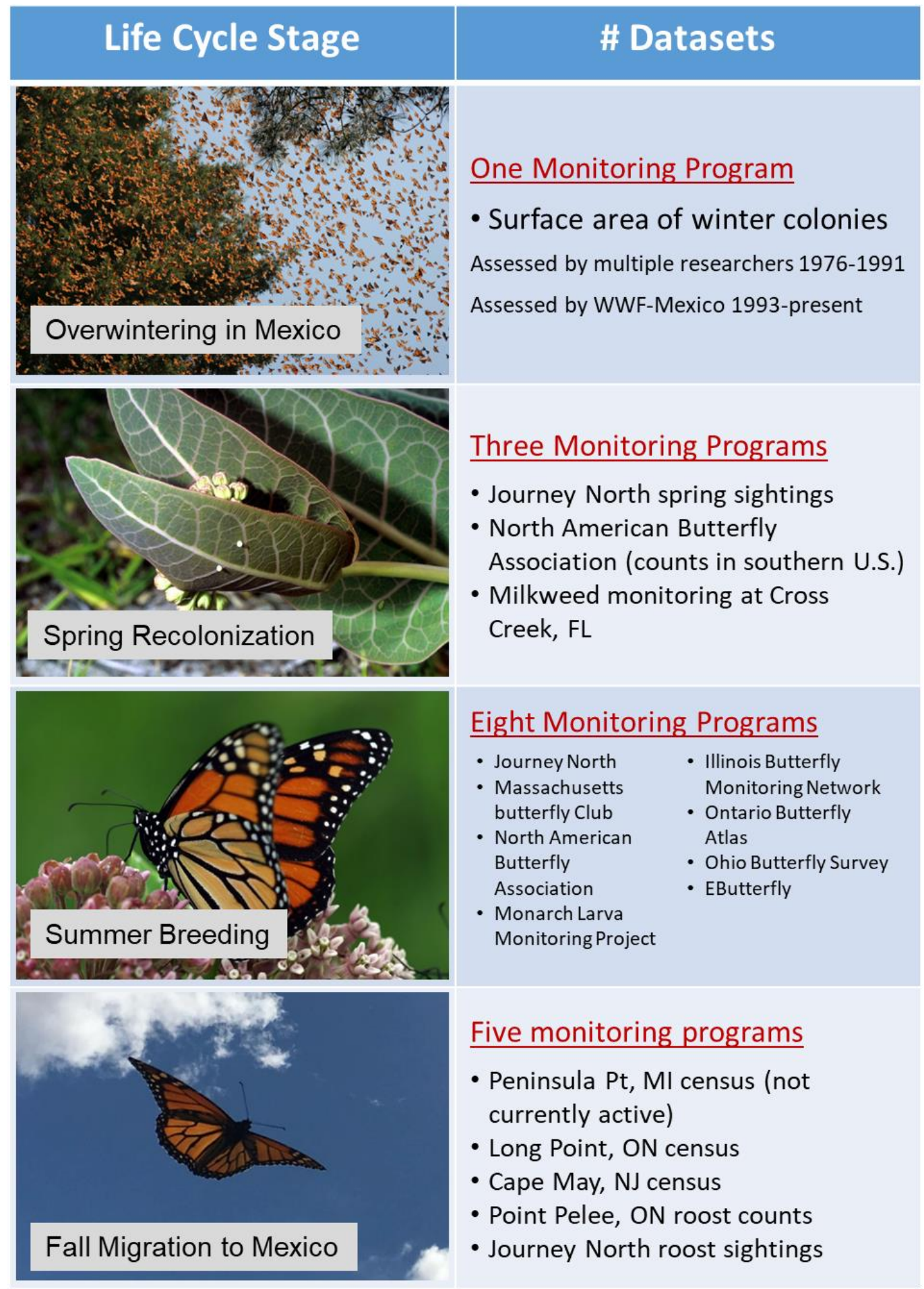


Importantly, the pattern seen at the winter colonies in the past two decades may not be reflected in abundance data obtained during other seasons. Even 10 years ago, it was clear that annual counts of migrating monarchs from two monitoring sites showed no evidence of long-term decline, which challenged the idea that the entire population was in decline, and suggested instead the declines may be confined to specific seasons (Davis 2012). This idea was later bolstered with more evidence from surveys of breeding adult abundance or additional migration data, which also showed no long-term decline (Badgett and Davis 2015, Ries et al. 2015, Inamine et al. 2016, Agrawal and Inamine 2018). These conclusions have themselves been challenged on the basis of the appropriateness of the various datasets, including the location of the migration monitoring sites (Brower et al. 2012a) or that the survey locations of breeding monarchs were not random on the landscape (Pleasants et al. 2015, Pleasants et al. 2017). Each of these arguments is fair, and in fact, new research has confirmed that non-randomly selected monitoring sites do not provide a complete picture of butterfly abundance (Kinkead et al. 2019). Collectively, this long-running debate has shown how difficult it can be to infer large-scale population changes from one or a select few datasets, since each has strengths and weaknesses.

To date, the majority of research examining long-term trends in monarch abundance has focused only on data from selected monitoring programs (e.g. Brower et al. 2012b, Badgett and Davis 2015, Davis and Dyer 2015, Saunders et al. 2018, Crewe et al. 2019), which makes it easy to be critical of the program's procedures or placement of monitoring sites (Brower et al. 2012a, Pleasants et al. 2015, Pleasants et al. 2017, Malcolm 2018). A more comprehensive approach would be to compile all available longterm data, across the entire annual cycle, and to systematically look for consistencies across projects. While this would not alleviate methodological issues with certain programs, if there are consistencies across monitoring projects using completely different procedures and from very different locations, it would be especially informative, and indicative of a real biological pattern. With this in mind, I set out to compile all available evidence to date on the status of the eastern monarch population, in an effort to obtain the most up-to-date and comprehensive picture of its status. This effort even included obtaining more complete data on the eastern monarch winter colonies than what has been made public, in the form of records dating back to the late 1970s. The timing of this effort is especially relevant; in the last 2-3 years, there has been a noticeable increase in summer abundance of monarchs (O. Taylor, pers. comm.), which means studies based on census data before this increase may no longer be accurate. Also, given that the USFWS is currently deliberating on whether monarchs require federal protection in the United States (USFWS 2020), this review should be especially relevant to those currently deciding the monarchs' fate. 


\section{Review of literature}

In the spring and summer of 2020, I conducted an exhaustive review of peer-reviewed and grey literature in an effort to identify all possible sources of data on monarch abundance through time within the eastern North American range. Of course this effort included obtaining the well-known winter colony data for the eastern population from WWF-Mexico. These records begin in the winter of 1993-94. However, I also supplemented these data with archived records of winter colony size that date back to the year following their discovery in Mexico, in 1976. These early records have been published in several places, including García-Serrano et al. (2004), Calvert and Brower (1986) and Mawdsley et al. (2020), as well as in an unpublished student thesis from Mexico (Mejía 1996). See the supplemental file for more details.

My efforts to obtain data from outside the winter range involved combing the scientific and grey literature for information on monarch abundance over time. Thus, this review included recent peer-reviewed publications, where either online material included actual raw data, or where graphs were presented, and from which the relevant data (monarch abundance) could be extracted. It also included grey literature, such as publicly-available online material (newsletters, citizen science program websites), where either raw data were given in tabular form or where graphs were presented. If a source only presented a graph of monarch abundance, I extracted the necessary pieces of information from the graph (monarch abundance per year) using image analysis software. I also personally contacted leaders of known butterfly monitoring programs to request historical and most recent data on monarch abundance (see contacts in Table 1).

For each data source, I specifically extracted information on the abundance of monarchs in each of the years covered. If multiple surveys were conducted per year I used the average annual count. In the end, each dataset consisted of a single column of annual indices, along with the year of the census (i.e. one index per year). Once all datasets were obtained, I looked for evidence of a temporal trend in each dataset individually using Pearson correlation (year vs monarch count). In selected cases this simple pairwise test was not appropriate, because of inherent issues with data collection, and these cases are outlined in the supplemental file. The goal here was not to find out which dataset correlated with which, only to determine if each one showed a directional trend. In other words, the goal was to determine if the dataset(s) indicated that monarchs were increasing, decreasing or have not changed over time.

\section{Monarch datasets}

I identified 20 different long-tern datasets and studies that have tracked monarch abundance over time, and in which data were made publically available, or provided to me directly by the author or program coordinator (Table 1). These included the one dataset of winter colony size from Mexico, 3 projects focusing on abundance during 
spring migration, 11 projects examining monarch abundance during summer, and 5 fall migration monitoring projects. These projects vary in methodology and in geographic scope, ranging from long-term counts made by a single individual, to sightings from groups of naturalists all within one state, to regional compilations of sightings from across the entire breeding, or migration range. Thirteen of the 20 datasets come entirely from ongoing citizen science programs, with the remaining being data from more detailed investigations conducted by scientists (but often using citizen science data).

Table 1 also briefly describes the methodology of each project, though for more detailed descriptions, see the supplemental file to this article. For most of the citizen science projects, the data obtained represent counts or compilations of monarch sightings from across the survey sites, transects, etc. In these projects, the average count per year was of importance, and is what was used as the unit of replication in analyses here. Additionally, there were two citizen science projects where sightings or records of monarchs were used to generate estimates of the geographic coverage of the monarchs' annual distribution, which can be another way to gauge annual changes in population size. In one of these studies, Flockhart et al. (2019) estimated the yearly geographic size of the Canadian breeding range using sightings from e-butterfly (www.e-butterfly.com) and Journey North (https://journeynorth.org/monarch/). Meanwhile, Journey North sightings have been used in the past to estimate temporal changes in the geographic size of the early spring migration wave, plus the summer breeding distribution (Howard and Davis 2015). Here, I used these published annual indices of spring and summer range size, and also calculated similar indices for all years since that study.

Two other projects were included here that are not necessarily based on citizen science or other monitoring data, but they are highly-relevant scientific investigations. One project was conducted to estimate breeding locations of monarchs that reached the Mexico colonies by using isotopic analyses of wing tissue (Flockhart et al. 2017). This project allowed for year-to-year comparisons of the relative production of different regions of the monarch range, going back to the discovery of the winter colonies in the mid-1970s. Of particular importance is that one of the regions examined is the American Midwest (the core breeding range of the eastern monarch). In essence then, the study provides a long-term view of the importance of the Midwest region for producing monarchs that end up at the winter colonies. I refer to these annual estimates here as "Midwestern monarch production estimates" (Table 1).

Another project of interest is the century-long survey of museum records that was recently published (Boyle et al. 2019). This project attempted to derive annual estimates of monarch abundance via these historical records, to track changes in abundance over the last century. This is indeed a worthwhile goal, but unfortunately the authors used an inappropriate means of controlling for sample effort and outlying years, which was pointed out in rebuttal articles (Ries et al. 2019, Wepprich 2019). In their rebuttal article, Ries et al. (2019) presented the same data after correctly controlling for these issues, and 
these "corrected" museum data were used for inclusion in this review (data was extracted from Fig. 2C). Thus, these records reflect the proportion of butterfly specimens that were monarchs, dating back to 1906 !

Table 1 (following page). Summary of monitoring programs, datasets and scientific publications where monarch abundance anywhere in eastern North America has been tracked over time. For detailed descriptions of methodology within each program or study, see Supplemental file. For most datasets, I examined the relationship between year and monarch abundance (using the annual index specific to each dataset) using Pearson correlation. Exceptions to this approach are noted in supplemental file. Results are colorcoded, where red shading represents significant declines, green reflects data with no statistical temporal change, and yellow are datasets that show a significant increase over time. 


\begin{tabular}{|c|c|c|c|c|c|c|}
\hline Dataset & Range & Season & Scope/Region & Methodology & Trend & Source \\
\hline $\begin{array}{l}\text { Mexico winter colony size } \\
\text { estimates }\end{array}$ & $1977-2019$ & Winter & Central Mexico & $\begin{array}{l}\text { Estimates of total surface area occupied by } \\
\text { monarchs, across all winter colonies }\end{array}$ & $\begin{array}{c}\text { Declining } \\
\text { (beta=-.19, } \\
p=0.031 \text { ) }\end{array}$ & $\begin{array}{l}\text { WWF Mexico, Calvert and Brower 1986, } \\
\text { Mejia 1996, Brower unpubl. data }\end{array}$ \\
\hline $\begin{array}{l}\text { Spring Surveys at Cross } \\
\text { Creek, FL }\end{array}$ & 1994-2017 & Spring & $\begin{array}{l}\text { Single site in North- } \\
\text { Central Florida }\end{array}$ & $\begin{array}{l}\text { Annual counts of arriving adults and } \\
\text { immatures in a cattle pasture ( } 9 \text { ha) at Cross } \\
\text { Creek in Alachua Co., FL }\end{array}$ & $\begin{array}{l}\text { Declining }(r=- \\
0.67, p=0.003)\end{array}$ & Brower et al 2019, extracted from figure \\
\hline $\begin{array}{l}\text { North American Butterfly } \\
\text { Association (spring } \\
\text { counts) }\end{array}$ & 2005-2014 & Spring & $\begin{array}{l}\text { States of TX, OK, AK and } \\
\text { MS }\end{array}$ & $\begin{array}{l}\text { Volunteer surveys of adult butterflies at sites } \\
\text { (15 mile diameter circles) within the spring } \\
\text { colonizationflyway in March-June }\end{array}$ & $\begin{array}{l}\text { Declining }(r=- \\
0.74, p=0.015)\end{array}$ & Inamine et al 2016, extracted from figure \\
\hline $\begin{array}{l}\text { Journey North (spring } \\
\text { sightings) }\end{array}$ & 1997-2018 & Spring & $\begin{array}{l}\text { Southern states prior to } \\
\text { April } 30\end{array}$ & $\begin{array}{l}\text { Total surface area of the earlyspring } \\
\text { migration wave, estimated from sightings of } \\
\text { returning adults }\end{array}$ & $\begin{array}{l}\text { Declining } \\
\text { (beta=-.38, } \\
p=0.094)^{*}\end{array}$ & $\begin{array}{l}\text { Howard and Davis } 2015 \text { (updated with } \\
\text { 2016-2018data) }\end{array}$ \\
\hline $\begin{array}{l}\text { North American Butterfly } \\
\text { Association (summer } \\
\text { counts) }\end{array}$ & 1993-2017 & Breeding & $\begin{array}{l}\text { Entire eastern breeding } \\
\text { range }\end{array}$ & $\begin{array}{l}\text { Volunteer surveys of adult butterflies at sites } \\
\text { (15 mile diameter circles) throughout breeding } \\
\text { range }\end{array}$ & $\begin{array}{l}\text { No change } \\
(r=-0.01 \\
p=0.981)\end{array}$ & $\begin{array}{l}\text { Agrawal and Inamine 2018, from suppl. } \\
\text { data }\end{array}$ \\
\hline $\begin{array}{l}\text { Monarch Larva } \\
\text { Monitoring Program }\end{array}$ & $1997-2018$ & Breeding & $\begin{array}{l}\text { Entire eastern breeding } \\
\text { range }\end{array}$ & $\begin{array}{l}\text { Weekly counts by volunteers of eggs and } \\
\text { larvae on milkweed at sites throughout } \\
\text { breeding range (peak season counts used for } \\
\text { annual index) }\end{array}$ & $\begin{array}{l}\text { No change } \\
(r=0.34 \\
p=0.143)\end{array}$ & $\begin{array}{l}\text { MLMP Spring } 2019 \text { newsletter } \\
\text { (https://monarchlab.org/images/uploads/ } \\
\text { mlmp_newsletters/Spring_2019_MLMP_U } \\
\text { pdate.pdf), extracted fromfigure }\end{array}$ \\
\hline $\begin{array}{l}\text { Midwestern monarch } \\
\text { production estimates }\end{array}$ & 1975-2014 & Breeding & $\begin{array}{l}\text { Midwest region (core } \\
\text { breeding area) }\end{array}$ & $\begin{array}{l}\text { Annual proportion of monarchs that are } \\
\text { estimated to come from Midwest, based on } \\
\text { isotopic signatures of Mexico samples }\end{array}$ & $\begin{array}{l}\text { No change } \\
(r=0.18 \\
p=0.459)\end{array}$ & Flockhart et al 2017, extracted from figure \\
\hline $\begin{array}{l}\text { Illinois butterfly } \\
\text { Monitoring Network }\end{array}$ & $1993-2019$ & Breeding & State of Illinois & $\begin{array}{l}\text { Walking Pollard transects conducted between } \\
\text { June } 1 \text { and August } 7 \text { ( } 6 \text { visits per season) }\end{array}$ & $\begin{array}{l}\text { No change } \\
(r=-0.31 \\
p=0.114)\end{array}$ & Doug Taron, pers. comm. \\
\hline $\begin{array}{l}\text { Journey North (summer } \\
\text { sightings) }\end{array}$ & 1994-2019 & Breeding & $\begin{array}{l}\text { Entire eastern breeding } \\
\text { range }\end{array}$ & $\begin{array}{l}\text { Annual size (surface area) of eastern breeding } \\
\text { range, estimated from maps of sightings of } \\
\text { adult monarchs }\end{array}$ & $\begin{array}{l}\text { Increasing } \\
\text { (beta }=0.83 \text {, } \\
p<0.001)^{*}\end{array}$ & $\begin{array}{l}\text { Howard and Davis } 2015 \text { (updated with } \\
\text { 2016-2019 data) }\end{array}$ \\
\hline Ontario Butterfly Atlas & 2003-2017 & Breeding & Province of Ontario & $\begin{array}{l}\text { Annual counts of breeding monarchs at sites } \\
\text { throughout Ontario, Canada }\end{array}$ & $\begin{array}{l}\text { No change } \\
(r=-0.19 \\
p=0.490)\end{array}$ & Crewe et al 2019, extracted fromfigure \\
\hline Ebutterfly, Journey North & 2000-2015 & Breeding & $\begin{array}{l}\text { Entire breeding range in } \\
\text { eastern Canada }\end{array}$ & $\begin{array}{l}\text { Breeding range size of monarchs in allof } \\
\text { eastern Canada, based on citizen scientist } \\
\text { sightings }\end{array}$ & $\begin{array}{l}\text { No change } \\
(r=0.42, \\
p=0.103)\end{array}$ & Flockhart et al 2019, extracted from figure \\
\hline $\begin{array}{l}\text { Iowa Multiple Species } \\
\text { Inventory and Monitoring } \\
\text { (MSIM) Program }\end{array}$ & 2006-2019 & Breeding & Sites throughout lowa & $\begin{array}{l}\text { Pollard walk transects censused up to } 4 \text { times } \\
\text { per summer. Only randomly-chosen sites } \\
\text { included here. }\end{array}$ & $\begin{array}{l}\text { No change } \\
(r=-0.12 \\
p=0.693)\end{array}$ & $\begin{array}{l}\text { Kincaid et al 2019, updated with recent } \\
\text { data }\end{array}$ \\
\hline $\begin{array}{l}\text { Massachusetts Butterfly } \\
\text { Club }\end{array}$ & 1992-2019 & $\begin{array}{l}\text { Breeding } \\
\text { and Fall }\end{array}$ & State of Massachusetts & $\begin{array}{l}\text { Butterfly walks by club members conducted } \\
\text { throughout the summer and fall in varying } \\
\text { locations (annual index used here is the sum } \\
\text { of monarchs/number of reports) }\end{array}$ & $\begin{array}{l}\text { No change } \\
(r=0.14, \\
p=0.486)\end{array}$ & $\begin{array}{l}\text { Mass Butterfly Club, unpubl data } \\
\text { (obtained with permission) }\end{array}$ \\
\hline Ohio butterfly Survey & 1996-2016 & $\begin{array}{l}\text { Breeding } \\
\text { and Fall }\end{array}$ & State of Ohio & $\begin{array}{l}\text { Weekly transect surveys of all butterflies at } \\
\text { sites in Ohio }\end{array}$ & $\begin{array}{l}\text { Ambiguous, } \\
\text { no clear trend }\end{array}$ & $\begin{array}{l}\text { Wepprichet al } 2019 \text {, plus personal } \\
\text { correspondence with program } \\
\text { coordinator** }\end{array}$ \\
\hline $\begin{array}{l}\text { Museum records of } \\
\text { monarchs }\end{array}$ & $1906-2013$ & $\begin{array}{l}\text { Breeding } \\
\text { and Fall }\end{array}$ & $\begin{array}{l}\text { Entire eastern breeding } \\
\text { range }\end{array}$ & $\begin{array}{l}\text { Proportion of (butterfly) museum specimens } \\
\text { that are monarchs, calculated each year }\end{array}$ & $\begin{array}{l}\text { Increasing } \\
(r=0.26 \\
p=0.011)\end{array}$ & Ries et al. 2019, extracted from figure \\
\hline $\begin{array}{l}\text { Peninsula Point, MI, } \\
\text { Migration Counts }\end{array}$ & 1996-2014 & Fall & $\begin{array}{l}\text { Single site in Michigan, } \\
\text { but captures } \\
\text { southbound-travelling } \\
\text { monarchs }\end{array}$ & $\begin{array}{l}\text { Dailycensuses of migrant monarchs at a } \\
\text { stopover site }\end{array}$ & $\begin{array}{l}\text { No change } \\
(r=0.16 \\
p=0.509)\end{array}$ & Bagett and Davis 2015 \\
\hline $\begin{array}{l}\text { Long Point Monarch } \\
\text { Migration Monitoring } \\
\text { Program }\end{array}$ & 1995-2019 & Fall & $\begin{array}{l}\text { Single site in southern } \\
\text { Ontario, but captures } \\
\text { southbound-travelling } \\
\text { monarchs }\end{array}$ & $\begin{array}{l}\text { Dailysurveys of fallmigrating monarchs at two } \\
\text { locations along the Long Point peninsula (both } \\
\text { sites pooled here) }\end{array}$ & $\begin{array}{l}\text { No change } \\
\qquad(r=-.24, \\
p=0.129)\end{array}$ & $\begin{array}{l}\text { Long Point, unpubl. data (obta ined from } \\
\text { NatureCounts web portal) }\end{array}$ \\
\hline $\begin{array}{l}\text { Cape May Migration } \\
\text { Monitoring Program }\end{array}$ & $1992-2018$ & Fall & $\begin{array}{l}\text { Single site in New Jersey, } \\
\text { but captures } \\
\text { southbound-travelling } \\
\text { monarchs }\end{array}$ & $\begin{array}{l}\text { Dailycounts of migrants intown of Cape May, } \\
\text { NJ }\end{array}$ & $\begin{array}{l}\text { No change } \\
(r=-0.07 \\
p=0.721)\end{array}$ & $\begin{array}{l}\text { From data provided at } \\
\text { www.monarchmonitoringproject.com }\end{array}$ \\
\hline $\begin{array}{l}\text { Point Pelee, ON roost } \\
\text { count }\end{array}$ & 1984-2018 & Fall & $\begin{array}{l}\text { Single site in southern } \\
\text { Ontario, but captures } \\
\text { southbound-travelling } \\
\text { monarchs }\end{array}$ & $\begin{array}{l}\text { Annual census of monarchs roosting at the tip } \\
\text { of the peninsula during migration }\end{array}$ & $\begin{array}{l}\text { No change } \\
(r=0.02, \\
p=0.930)\end{array}$ & $\begin{array}{l}\text { From data provided in Ethier } 2020 \\
\text { (extracted from Fig 2C) }\end{array}$ \\
\hline
\end{tabular}


*Annual indices of breeding range size from Journey North observations are confounded by increases in observers over time. Shown is the effect of year in a regression model that examined changes in surface area, while taking into account number of observers. See Howard and Davis (2015).

** Tyson et al 2019 examined these data up to 2016 and reported a modest decline, which was driven by two early peak years. Subsequently, the volunteers report a major rebound in abundance ( $\mathrm{J}$. Weidman, pers. comm.), though the latest data is not yet available.

\section{Summary of results}

For each monarch dataset I report whether there has been an increase, decline, or no change over time in Table 1, which is based on a simple pairwise correlation test (year vs monarch count). Note that the raw data from these programs is intentionally not presented in this review, since 1) most of these data come from public sources or alreadypublished manuscripts, and 2) those program managers who kindly shared unpublished data with me deserve the exclusive right to conduct and publish their own (and more thorough) studies with their data. However, I have included a visual depiction of trends from selected datasets (Fig. 3), without showing actual numbers. These graphs are only intended to depict 1) the varying (temporal) nature of monarch abundance, and 2) the overall trend over time, if any, for these selected datasets.

Importantly, a distinct pattern is evident when the datasets, and their results are arranged by season, as is shown in Table 1. Below I outline the results in order of season.

\section{Winter patterns}

- When the total colony size across all 44 years with data is graphed, it appears to show a visible pattern of increase in the early years, peaking in the 1990s, followed by a decline (Fig. 2, and see supplemental file). This is misleading however, since the early researchers did not measure all of the colonies. When the colony number is accounted for, a linear regression of these data shows there has been a slight but significant linear decline over this time $(\mathrm{p}=0.031)$. However, a comparison of average colony sizes across decades shows the colony sizes in the last decade are not significantly different than they were in the 1970s and 80s. An alternative approach that used data from the largest colony (El Rosario) to estimate total colony size in the early years did show a modest decline from the mid-1980s onward ( $\mathrm{p}=0.002)$. Further details of these analyses are provided in the supplemental file.

- A reasonable interpretation of these results is that the Mexican winter colonies show evidence of some long-term decline, but the magnitude is not as large as once thought (i.e. not $80 \%$ ). Also important is the fact that the current size of the colonies are similar to what they were 30 years ago. 


\section{Spring patterns}

- The number of adult monarchs observed in southern US states during April (which are largely spring migrants) by volunteers of the North American Butterfly Association also showed a significant decline (Inamine et al. 2016), although the range of years sampled is not large (9).

- The geographic coverage of the early spring recolonization wave, as measured by Journey North sightings (Howard and Davis 2015), has also been slowly shrinking with time, although the trend only approached significance $(\mathrm{p}=0.094)$.

- The number of eggs per milkweed plant has been declining during the early spring at a site in Central Florida (Brower et al. 2018).

\section{$\underline{\text { Summer abundance - state- and provincial-level results }}$}

- The number of monarchs counted by the Massachusetts Butterfly Club has not changed (i.e. no significant relationship with year) in 27 years (and see Fig. 2).

- The number of monarchs seen along transects by trained staff of the Iowa Dept of Natural Resources (Kinkead et al. 2019) has not declined in the last 13 years.

- There has been no significant change in the number of monarchs counted by volunteers of the Illinois Butterfly Monitoring Network over the last 26 years (Fig. 2).

- The number of monarchs counted in the Ohio Butterfly survey has varied markedly (Wepprich et al. 2019); early in the program there were two peak seasons, followed by many years of low numbers, and in the last few years the volunteers have observed a rebound. Overall though, this program does not appear to show a decline in monarch abundance in the state of Ohio. Note that this conclusion is also supported by the head of the monitoring program, as well as an independent researcher who examined a subset of these data (T. Wepprich, pers. comm.).

- The number of monarchs sighted by volunteers of the Ontario Butterfly Atlas (Crewe et al. 2019) did not change in 14 years (2003-2017; Fig. 2).

$\underline{\text { Summer abundance - regional programs composed of multiple states and provinces }}$

- The mean "peak summer density" of eggs and larvae in all Midwestern states, as reported by volunteers in the Monarch Larva Monitoring Program (Project 2019), did not change from 1997 to 2018 (Fig. 2).

- The average number of adult monarchs seen each summer by members of the National Butterfly Association has not changed between 1993 and 2017 (Inamine et al. 2016, Agrawal and Inamine 2018). This trend is also shown in figure 2.

- Based on isotope analyses of archived monarch specimens, it is clear that the production of monarchs from the American Midwest (reflected in the proportion of 
monarchs at the Mexican winter colonies) has varied over time but is not different in recent years than it was in the 1970s (Flockhart et al. 2017).

- The geographic size of the Canadian breeding range for the eastern population, based mapping sightings of adult monarchs (Flockhart et al. 2019), has expanded from 2000 to 2015 (and see Fig. 2).

- The number of monarch specimens deposited in museums each year (i.e. the proportion of all butterfly specimens that are monarchs) has not changed over the last 100 years (Ries et al. 2019).

\section{$\underline{\text { Results from surveys of fall migration }}$}

- The number of migratory monarchs counted at monitoring stations in both Michigan and New Jersey has not declined significantly over the last two decades (Badgett and Davis 2015, Cape May Monarch Monitoring Project 2019).

- The annual average number of monarchs counted at by staff at Long Point, ON (Crewe and McCracken 2015, Ethier 2020) showed a shallow downward trend since 1992, though this trend is not statistically significant using a Pearson correlation test $(\mathrm{r}=-0.2, \mathrm{p}=0.129)$. See Supplemental file for details about this dataset.

- The average size of roosts counted by volunteers at Point Pelee National Park (on the north shore of Lake Erie, Ontario) has not declined in 34 years (Ethier 2020).

- The average size of migratory roosts reported by citizens from across the fall flyway (reported to Journey North) has not changed in the last 17 years (Journey North 2019).

\section{Interpretation of the collective results}

Based on this analysis of 20 different datasets on monarch abundance, reproductive success or migration size, and from across the entire annual cycle, it is clear that there has been a modest decline in the winter colony size over the last two decades, and a corresponding decline in the size of the recolonizing cohort in the spring. Indeed, all spring datasets show evidence of decline. This makes sense since the spring cohort is essentially the same generation of monarchs that depart from Mexico. In other words, the pattern of diminishing winter colony sizes is also being reflected in all spring population assessments. However, it is also clear that these declines in Mexico are not representative of the health of the overall monarch population in eastern North America. The losses being seen during winter and spring apparently are being offset by reproductive growth in the summer. None of the summer monitoring projects and datasets examined showed evidence of declining monarch abundance. In other words, the numbers of breeding monarchs, and the overall size of the eastern monarch breeding range, both in the US and Canada, is not diminishing. If anything, all evidence indicates the eastern breeding range is expanding; two different datasets indicate that the distributional range of eastern 
monarchs in both Canada, and the US is increasing (Howard and Davis 2015, Flockhart et al. 2019).

Similarly, the overall size of the fall migration each year shows little signs of decline; average roost sizes have not declined, nor have counts of monarchs seen during migratory surveys at two of three monitoring stations (Cape May and Peninsula Point). One exception appears to be at the long-term monarch monitoring project at Long Point, Ontario, where over the last 30 years there has been a shallow but non-significant decline $(\mathrm{r}=-0.24, \mathrm{p}=0.129)$, based on the pairwise Pearson correlation test used here. When these same data were examined in a more comprehensive manner, and taking into account weather variables, this decline was significant (Crewe and McCracken 2015, Ethier 2020). See supplemental file for more details.

Of particular importance is the consistency in the datasets. All surveys and projects conducted during spring showed evidence of declines. Meanwhile, all data obtained during the summer show no declines, and all but one dataset from the fall show no declines. Each dataset has drawbacks, including non-random placement of survey sites (Kinkead et al. 2019), variation in observer effort over time (Howard and Davis 2015), and pseudoreplication (especially at migration monitoring sites). Indeed, a number of legitimate arguments could be made against using any one dataset to draw sweeping conclusions toward the entire population. However, the consistency across 16 different long-term summer and fall projects, and from different regions of the eastern monarch range (and two countries), cannot be argued with. From this there can be no doubt - the eastern monarch population is not in danger or even threatened, despite the diminishing winter colonies over the last two decades.

\section{Parallel evidence from new genetic research}

The conclusion that the eastern monarch population is not in danger is wellsupported by the numerous datasets reviewed here, and also by new genetic evidence, which, at the time of this writing, is in preparation for submission. Briefly, Talla and de Roode compared the genomic diversity of archived monarch specimens from the late 1970s to those of modern specimens to look for evidence of change in genetic diversity that might indicate a declining population. Their analysis focused on specimens obtained from the winter colonies in 1977, plus those obtained from these same colonies in the last 10 years as well as monarchs collected within the breeding range.

They report that not only has there been no decline in genetic diversity in the last $40+$ years, but in fact diversity may have even increased. Therefore from a genetic standpoint, there is not yet any signal that the population is or has been declining (Talla and de Roode, manuscript in prep). 
Figure 2. Comparison of long-term trends in monarch abundance across 6 different summer monitoring programs and the annual census of winter colony size in Mexico. Note that these datasets do not represent the entirety of the projects included in this review. In each case shown, the approximate geographic coverage of the program in North America is depicted. Each graph depicts the annual index of monarch abundance from each program through time (units are not shown). Of importance is the direction (or lack of direction) of the trend in each case.

\section{Data Source Coverage Long-term Trend}

Massachusetts
Butterfly club
(1992-2019)


* The data from the winter colony size was a compilation of the WWF-Mexico dataset, which began in the winter of 1993-94, plus records from earlier researchers, who also measured colony sizes. See the supplemental file for more information on these earlier measurements, plus how these colony data were analyzed.

\section{Is milkweed really limiting to monarchs?}

The results of both this review, and the aforementioned genetic study, bear directly on the ongoing debate over the cause of the winter declines. In the past decade, a virtual mountain of media reports, together with writings from a number of scientists (Pleasants and Oberhauser 2013, Semmens et al. 2016, Pleasants 2017, Thogmartin et al. 2017b), have all repeatedly touted how the entire eastern monarch population is declining because of declines in agricultural milkweed in the core breeding range of the American Midwest. The majority of these claims have been made based on the fact that winter colony declines have coincided with the rise in genetically-modified corn and soy, which allows farmers to spray herbicide over their fields. It is true that the onset of roundupready crops in the mid-1990s has dramatically reduced the milkweed that used to reside within agricultural crops in the Midwest, and this is not debatable (Hartzler 2010). Moreover, the agricultural landscape itself in the United States has experienced changes in farm composition and management over time, which also has led to altered milkweed availability (Zaya et al. 2017). Add to this, the fact that a number of studies have shown statistical evidence implicating roundup-ready crops in the decline of winter colonies (Brower et al. 2012b, Pleasants and Oberhauser 2013, Thogmartin et al. 2017b). One naturally wonders then, with seemingly so much agricultural milkweed being lost, especially in the last 20 years, how is it possible that monarchs are not declining within their breeding phase? This author proposes that the collective monarch population was never as dependent on agricultural milkweed as we once thought. If one considers the original study that appeared to identify the American Midwest as the "core" monarch breeding range (Wassenaar and Hobson 1998), it is important to remember that it was conducted using samples from only one season (1997), and in that year 50\% of the wintering monarchs originated from the Midwest. We now know that was an outlier year, based on a more thorough examination of monarch specimens over 38 years (Flockhart et al. 2017). It turns out that the Midwest really only contributes $38 \%$ to the winter colonies, while $62 \%$ of all monarchs at the winter colonies come from regions outside of the agricultural Midwest. Therefore, this region is not as important as we once thought to the overall (winter) population.

It is also worth pointing out that the majority of evidence that has been built to support the claim that milkweed is limiting has been correlative in nature; the rise in use of roundup-ready crops in the United States since the mid-1990s has temporally coincided with the declines in winter colony size that began in the late 1990s. This claim has been suggested numerous times in studies using a variety of simple or complex 
statistical approaches (Brower et al. 2012b, Flockhart et al. 2015, Thogmartin et al. 2017b). Regardless of the approach, apparently the annual increases in roundup-ready crop use are always a significant predictor of the annual declines in winter colony area. While these approaches, and statistical models are not wrong per se, it does need to be remembered that any model will find a significant relationship between two phenomena that change at the same rate, even if they are not at all related. The fact that usage of roundup-ready crops rose at the same time as monarch winter colony sizes declined is not definitive proof of cause-and-effect, even if there is a statistical relationship.

One could also ask how monarchs are not declining given that natural insect habitats (fields, meadows, grasslands) are clearly declining within their breeding range (Wimberly et al. 2017). Here it could be pointed out that monarchs are capable of utilizing a variety of human-altered landscapes, which may be sufficient to offset losses of natural habitats. It should not be overlooked that milkweed thrives in disturbed landscapes (Daniels et al. 2018, Haan and Landis 2019, Knight et al. 2019), which includes powerline cuts, railways, and other human-modified areas. In addition, we also know that monarch abundance is inversely associated with forest area (Saunders et al. 2018), meaning any forest clearing for human activities, while destructive, can in fact benefit monarchs. Monarchs even appear to prefer areas managed by burning over grazed lands (Leone et al. 2019). Collectively, this body of evidence speaks to the versatility and resilience of monarchs, and how they may be adapting to (even benefitting from) the wide scale anthropogenic changes being made to the landscape.

\section{Does the size of the winter colonies even matter?}

One take-home message of this review is that the eastern monarch breeding population appears capable of rebounding annually even from small winter colony sizes, such as those we have seen in recent years. This therefore begs the question, does it actually matter how big the winter colonies are? In fact, it may not; a series of studies from the last three years have now shown that the Mexico winter colony size does not (statistically) predict the size of the subsequent breeding population. This is true whether one examines data from the U.S. (Saunders et al. 2018) or further north in Canada (Crewe et al. 2019, Flockhart et al. 2019). What is now becoming apparent is that the environmental conditions during the spring recolonization phase are much more important for determining the success of the breeding stage (Saunders et al. 2018, Crewe et al. 2019), than is the size of the winter colony from year to year. This conclusion is also consistent with historical evidence after winter storms; there have been major mortality events associated with storms in 1981, 2002, and 2016. In 2002, an estimated $80 \%$ of the winter colonies were killed. Yet, in the following summer, the number of monarchs counted by the North American Butterfly Association was normal (i.e. close to average), as was the count of migrating monarchs that fall at Peninsula Point, MI (pers. $o b s$.). Collectively then, all evidence to date, either from recent studies of from historical 
observations, argues that the size of the Mexico winter colonies from year to year has little impact on the size of the summer and fall cohort in eastern North America. In other words, the size of the winter colonies appears to carry little to no information regarding the growth potential of the population each year.

\section{Reinterpreting the winter colony patterns with the "new" historical data}

Even though the most recent science argues that the Mexican winter colony size is unimportant, these data are nonetheless still being used to track population size over time in both public and scientific circles (i.e., i.e., Semmens et al. 2016, Thogmartin et al. 2017b, Saunders et al. 2019, Taylor et al. 2020). Indeed, a common narrative in the scientific as well as public realm over the last 10 years has been that "the eastern population has declined by $90 \%$." Notably, this claim has been made based on the winter colony trajectory from 1994 to present, which is when the colonies were assessed by WWF-Mexico. It just so happens that at the beginning of this timeframe, the winter colonies appeared to be exceptionally large. And, the colonies then diminished thereafter, so that the latest years' colonies are indeed approximately $90 \%$ smaller than they were in the mid-1990s. However, this picture changes if one examines the complete 40+ year dataset of colony size (Fig. 2, and see supplemental file), which shows an early increase, a peak in the 1990s and then a decline. In fact, the colonies from the most recent decade actually are not dissimilar from those in the 1970s or 80s. In this sense then, the winter colonies are NOT $90 \%$ lower than their historical level. If anything, it appears that the peak in the 1990s was an outlier decade over the 5 decades with data. Or perhaps the colonies have a natural cyclical pattern that plays out over long time spans.

Interestingly, few even know that these early records of colony size exist. At the time of this writing, I conducted an informal poll of 30 researchers and citizens with knowledge of monarchs (split evenly) and asked each to report when the Mexico colonies were first measured. Of the citizens, 90\% thought they began in 1994, when WWFMexico first started their assessments. Even $50 \%$ of the scientists I surveyed thought this too (unpubl. data). To be fair, the early records of Mexico colony sizes have generally not been publicly available, although they were included in a small chapter in the 2004 book, The Monarch Butterfly: Biology and Conservation (García-Serrano et al. 2004). Also, a recent opinion article published this year regarding the monarch conservation status included these early data as well (Mawdsley et al. 2020). 


\section{What is the reason for the disconnect between summer and winter patterns?}

A logical conclusion to draw from the fact that the winter colonies have declined in the last two decades, yet summer and fall abundance is unchanged, is that monarchs must be facing increasing problems in reaching the Mexican colony sites. This author proposed this idea 10 years ago (Davis 2012). This idea has since been embraced by a growing number of monarch researchers (Ries et al. 2015, Agrawal and Inamine 2018, Saunders et al. 2019), but it admittedly still requires further investigation. A recent study did begin to explore this idea, although with only 12 years of monitoring data from summer and fall (Saunders et al. 2019). Nevertheless, this investigation did show that winter colony sizes are indeed affected by poor migration resources. Even more recently, Taylor et al. (2019) showed (although anecdotally) that winter colony sizes can be negatively affected if the migration is late, which is yet more evidence that winter colony sizes are affected by the success of the fall migration.

New evidence has come to light that appears to run counter to this "migration mortality hypothesis", in the form of results from the long-term monarch tagging program, MonarchWatch. In this program, monarchs are tagged with numbered stickers by thousands of volunteers throughout the fall migration, and the same monarchs can be found at the overwintering colonies, usually by locals or guides. Taylor et al. (2020) compiled annual rates of tag recoveries for the eastern population over 15 years, which showed variation among years, but no long-term change. They argue that migratory mortality has not increased over time. While these tagging data are certainly valuable for research purposes (Davis 2015), this conclusion may be premature. One inherent limitation of these data is that the tag collecting effort at the winter colonies is not consistent from year to year, so that there is no way to know if changes (or lack of change) in annual recovery rates reflects a change in monarch migration patterns or a change in search effort for tags. Regardless of this problem, this new information has been peer-reviewed and therefore cannot be ignored in discussions over the cause of the declines in Mexico.

\section{Other possible explanations}

Since both the "milkweed limitation hypothesis" and the "migration mortality hypothesis" now have counter-evidence (Taylor et al. 2020, and this paper), it may be time to revisit the original question afresh, that is, what is causing the declines at the overwintering colonies? More importantly, it might be time to begin asking if there even is a decline in the more recent years. Consider that the size of the winter colonies in Mexico have always been measured by assessing the total area occupied by trees with monarch clusters, which is a crude metric, borne out of sheer necessity by on-the-ground researchers. However, one of the implicit assumptions of this approach is that the density 
of monarchs in the trees is unchanging over time. Indeed, attempts to calculate the true density have been difficult because on-the-ground estimates of cluster density have varied considerably between years (Thogmartin et al. 2017a). It should also be considered that there have been ongoing changes to the forests where the colonies occur, notably, logging of trees and forest fragmentation (Brower et al. 2002, Flores-Martinez et al. 2019). It is not known if this would cause colonies to become more tightly-packed within the remaining sections of forest. If it does, this simple change in monarch behavior could result in the "appearance" of smaller winter colonies over time, when in fact, the true winter abundance of monarchs is not changing. And, if this were the case, it would explain why counts made during the summer and fall are showing no decline (because there isn't one).

Another alternative explanation for the declines in winter but lack of declines in summer and fall relates to the winter location itself. There are approximately 10-15 known winter colonies in the mountains of Central Mexico that monarchs typically use, to varying degrees, in most years. It has always been assumed that these are the only winter colonies, largely from extensive searching of this region by researchers (reviewed in Slayback et al. 2007). In fact, aerial reconnaissance of the mountains where known colonies form appeared to indicate that monarchs only used those known locations. However, at the time these surveyed were conducted the flight team also reported that there were other mountainous locations that should be suitable, and that were not surveyed, either by air or by foot (Slayback et al. 2007). Moreover, earlier researchers "on the ground" in Mexico have previously stated that additional colonies continue to be found as time goes on, because of intensifying search effort (García-Serrano et al. 2004). Thus, it is entirely possible that there are other winter colonies that are not currently (or have ever been) surveyed annually. And without this information, we would never know if these "other" colonies are growing in size, while the known colonies are shrinking. Such a shift in monarch winter distribution could give the appearance of a decline at the known colonies, while the overall winter abundance remains unchanging.

Both of these hypothetical scenarios serve as a reminder that there is much we do not know about the biology of monarchs, and, how it may (or may not) be changing with ongoing anthropogenic pressures.

\section{Relevance to monarchs in western North America}

This review has focused exclusively on patterns and trends found in data from the eastern range of the North American monarch population, largely because of the wealth of data from this region. There are decidedly fewer long-term monitoring programs that track monarch or butterfly abundance in the western North American monarch range. The few data that are available appear to show a dramatic decline in overall population size, and this is especially obvious from long-term surveys of winter colonies along the 
California coastline (Schultz et al. 2017). A single long-term survey of breeding butterfly abundance in California also shows evidence of declines, although largely during the early part of the summer (Espeset et al. 2016).

One of the main lessons to be learned from the current review of eastern monarch datasets is that assessments of winter colony size alone do not paint an accurate picture of the long-term trajectory of the entire population. In fact, estimates from this single time period can even be misleading, when trying to extrapolate to the full annual cycle. As such, it would be important for those involved in management or conservation of western monarchs to be aware of this limitation. For the same reason, it would also be worthwhile to find ways in the future to evaluate this population based on information from nonwinter surveys. Given the dearth of long-term surveys in the west, it may be possible to examine long-term changes in breeding range size, as has been done in the east, both in the U.S. (Howard and Davis 2015) and in Canada (Flockhart et al. 2019). Alternatively, one could examine counts of museum specimens (Boyle et al. 2019), or perhaps use molecular approaches to compare archived (western) specimens to current ones, to deduce changes in genetic diversity, as was recently done in the east (Talla and de Roode, submitted).

\section{Recommendations for future science communications}

For the last 10 years there has been ongoing debate over how best to characterize the status of the eastern population, and whether it is truly declining (Brower et al. 2012a, Brower et al. 2012b, Davis 2012, Pleasants et al. 2015, Gustafsson 2017, Pleasants et al. 2017, Agrawal and Inamine 2018, Popkin 2020, Taylor et al. 2020). With the results shown here, combined with other recently presented results (Talla and de Roode, In Prep), it should be clear now that the eastern population is in no imminent danger, despite the recent reductions of their winter colonies. Moreover, these winter reductions appear to be minor when evaluated over a $40+$ year timespan. Thus, future communication (scientific writings, presentations) on the status of this population need to reflect this. This author proposes that instead of simply stating and re-stating the tired dogma that "eastern monarchs are declining", which is clearly not the case, presenters or writers could use terminology such as "eastern monarchs appear to be stable for now, despite diminishing winter colonies, but they face an uncertain future." Moreover, descriptions of the current trajectory of the winter colonies should be made without referring to this as the "population" trajectory, since the population is and should be a composite measure across all seasonal stages. After all, it is clear now that the trends observed in Mexico are not at all reflective of the population at other annual phases. And finally, presenting viewers and readers with all of the available evidence from the complete annual cycle of the monarch (as opposed to only the winter dataset) would be prudent, objective, and welcomed by this scientist. 


\section{Summary}

This synthesis of monarch butterfly census and abundance data represents the most comprehensive and detailed assessment of the eastern North American population to date, since it included 20 different datasets, each with far-ranging methodologies, to evaluate similarities and differences in long-term patterns across the annual cycle. Moreover, the datasets included the most up-to-date surveys and indices (many with data even from 2019), which reflect recent changes in abundance that may not have been evident in studies published even 3 years ago. Results of this review showed the winter colonies of eastern monarchs have been declining modestly over 40+ years, and all surveys of abundance (or recolonization range) completed during the spring recolonization period are also showing a declining trend. Despite this, there is little to no long-term decline in monarch abundance evident across 16 different monitoring projects conducted during summer and fall. These projects ranged from counts of eggs on milkweeds, to surveys of adults, to counts of roosting monarchs, and even specimen totals from museums. While each project has inherent methodological limitations, the fact that all of them show the same pattern, regardless of procedures, geographic position, coverage, etc., is undeniable. Moreover, this evidence is also consistent with new genetic research (submitted along with this paper) that confirms that eastern monarchs are expanding, not contracting.

Collectively, this evidence argues that 1 ) the recent winter colony declines do not reflect the status of the entire population, and 2) there is no limitation of milkweed throughout their breeding range (since true milkweed limitation would result in reduced summer abundance). Since there is no denying that changes in agricultural practices have eliminated the once-plentiful milkweeds in farm fields of the Midwest, the logical conclusion is that the population may not have been as dependent on agricultural milkweed as once thought, and/or it may be adapting to new human-modified habitats. Finally, this evidence has implications for the pending USFWS decision on whether to list the monarch as "threatened" in the United States. Based on the material examined here, this author argues the listing is not warranted. In fact, all evidence indicates that the eastern North American monarch population is doing just fine.

\section{Acknowledgements}

The author wishes to thank his many colleagues for spirited discussions on this topic, since such debate can often be the catalyst which propels science forward. Also, the majority of data examined here was obtained through the dedication and hard work by thousands of volunteers, butterfly counters, and citizen scientists. The author thanks these volunteers, plus the people who oversee these projects and manage their data. In particular, thanks to Doug Taron, Mark Fairbrother, and Karen Kinkead for supplying data on monarch abundance. 


\section{References}

Agrawal, A. A., and H. Inamine. 2018. Mechanisms behind the monarch's decline. Science 360: 1294-1296.

Badgett, G., and A. K. Davis. 2015. Population trends of monarchs at a northern monitoring site: analyses of 19 years of fall migration counts at Peninsula Point, MI. Annals of the Entomological Society of America 108: 700-706.

Basset, Y., and G. P. A. Lamarre. 2019. Toward a world that values insects. Science 364: 1230-+.

Black, S. H. 2019. Insect Apocalypse? What Is Really Happening; Why it Matters; and How We All Can Help, pp. 5-11, Wings Magazine, Xerces Society Newsletter.

Boyle, J. H., H. J. Dalgleish, and J. R. Puzey. 2019. Monarch butterfly and milkweed declines substantially predate the use of genetically modified crops. Proceedings of the National Academy of Sciences of the United States of America 116: 30063011.

Brower, L. P., O. R. Taylor, and E. H. Williams. 2012a. Response to Davis: choosing relevant evidence to assess monarch population trends. Insect Conservation and Diversity 5: 327-329.

Brower, L. P., O. R. Taylor, E. H. Williams, D. A. Slayback, R. R. Zubieta, and M. I. Ramirez. 2012b. Decline of monarch butterflies overwintering in Mexico: is the migratory phenomenon at risk? Insect Conservation and Diversity 5: 95-100.

Brower, L. P., G. Castilleja, A. Peralta, J. Lopez-Garcia, L. Bojorquez-Tapia, S. Diaz, D. Melgarejo, and M. Missrie. 2002. Quantitative changes in forest quality in a principal overwintering area of the monarch butterfly in Mexico, 1971-1999. Conservation Biology 16: 346-359.

Brower, L. P., E. H. Williams, K. S. Dunford, J. C. Dunford, A. L. Knight, J. Daniels, J. A. Cohen, T. Van Hook, E. Saarinen, M. J. Standridge, S. W. Epstein, M. P. Zalucki, and S. B. Malcolm. 2018. A long-term survey of spring monarch butterflies in north-central Florida. Journal of Natural History 52: 20252046.

Calvert, W. H., and L. P. Brower. 1986. The location of monarch butterfly (Danaus plexippus L.) overwintering colonies in Mexico in relation to topography and climate. Journal of the Lepidopterists' Society 40: 164-187.

Cape May Monarch Monitoring Project. 2019. Census Results https://capemaymonarchs.blogspot.com/2020/09/census-results-week-1.html.

Center for Biological Diversity. 2014. Petition to Protect the Monarch Butterfly (Danaus plexippus plexippus) Under the Endangered Species Act. Available online at:

https://www.biologicaldiversity.org/species/invertebrates/pdfs/Monarch_ESA_Pet ition.pdf.

Crewe, T. L., and J. D. McCracken. 2015. Long-term trends in the number of monarch butterflies counted on fall migration at Long Point, Ontario, Canada (1995-2014). Annals of the Entomological Society of America 108: 707-717.

Crewe, T. L., G. W. Mitchell, and M. Larrivee. 2019. Size of the Canadian breeding population of monarch butterflies is driven by factors acting during spring migration and recolonization. Frontiers in Ecology and Evolution 7: 12. 
Crossley, M. S., A. R. Meier, E. M. Baldwin, L. L. Berry, L. C. Crenshaw, G. L. Hartman, D. Lagos-Kutz, D. H. Nichols, K. Patel, S. Varriano, W. E. Snyder, and M. D. Moran. 2020. No net insect abundance and diversity declines across US long term ecological research sites. Nature Ecology and Evolution 10 August 2020.

Daniels, J., C. Kimmel, S. McClung, S. Epstein, J. Bremer, and K. Rossetti. 2018. Better understanding the potential importance of Florida roadside breeding habitat for the monarch. Insects 9: 8.

Davis, A. K. 2012. Are migratory monarchs really declining in eastern North America? Examining evidence from two fall census programs. Insect Conservation and Diversity 5: 101-105.

Davis, A. K. 2015. Opinion: conservation of monarch butterflies (Danaus plexippus) could be enhanced with analyses and publication of citizen science tagging data. Insect Conservation and Diversity 8: 103-106.

Davis, A. K., and L. Dyer. 2015. Long-term trends in eastern North American monarch butterflies: a collection of studies focusing on spring, summer, and fall dynamics. Annals of the Entomological Society of America 108: 661-663.

Didham, R. K., F. Barbero, C. M. Collins, M. L. Forister, C. Hassall, S. R. Leather, L. Packer, M. E. Saunders, and A. J. A. Stewart. 2020. Spotlight on insects: trends, threats and conservation challenges. Insect Conservation and Diversity 13: 99-102.

Diffendorfer, J. E., W. E. Thogmartin, R. G. Drum, and C. Schultz. 2020. North American Monarch Butterfly Ecology and Conservation. Frontiers in Ecology and Evolution.

Espeset, A. E., J. G. Harrison, A. M. Shapiro, C. C. Nice, J. H. Thorne, D. P. Waetjen, J. A. Fordyce, and M. L. Forister. 2016. Understanding a migratory species in a changing world: climatic effects and demographic declines in the western monarch revealed by four decades of intensive monitoring. Oecologia 181: 819-830.

Ethier, D. 2020. Population trends of Monarch butterflies (Danaus plexippus) migrating from the core of Canada's eastern breeding population. Annals of the Entomological Society of America.

Flockhart, D. T. T., J. B. Pichancourt, D. R. Norris, and T. G. Martin. 2015. Unravelling the annual cycle in a migratory animal: breeding-season habitat loss drives population declines of monarch butterflies. Journal of Animal Ecology 84: 155-165.

Flockhart, D. T. T., M. Larrivee, K. L. Prudic, and D. R. Norris. 2019. Estimating the annual distribution of monarch butterflies in Canada over 16 years using citizen science data. Facets 4: 238-253.

Flockhart, D. T. T., L. P. Brower, M. I. Ramirez, K. A. Hobson, L. I. Wassenaar, S. Altizer, and D. R. Norris. 2017. Regional climate on the breeding grounds predicts variation in the natal origin of monarch butterflies overwintering in Mexico over 38 years. Global Change Biology 23: 2565-2576.

Flores-Martinez, J. J., A. Martinez-Pacheco, E. Rendon-Salinas, J. Rickards, S. Sarkar, and V. Sanchez-Cordero. 2019. Recent forest cover loss in the core zones of the monarch butterfly biosphere reserve in Mexico. Frontiers in Environmental Science 7: 8. 
Forister, M. L., E. M. Pelton, and S. H. Black. 2019. Declines in insect abundance and diversity: We know enough to act now. Conservation Science and Practice DOI: $10.1111 / \operatorname{csp} 2.80$.

García-Serrano, E., J. Lobato Reyes, and B. X. M. Alvarez. 2004. Locations and area occupied by monarch butterflies overwintering in Mexico from 1993 to 2002, pp. 129-133. In K. Oberhauser and M. Solensky (eds.), The monarch butterfly. Biology and conservation. Cornell University Press.

Gustafsson, K. M. 2017. Narrating the monarch butterfly: managing knowledge complexity and uncertainty in coproduction of a collective narrative and public discourse. Science Communication 39: 492-519.

Gustafsson, K. M., A. A. Agrawal, B. V. Lewenstein, and S. A. Wolf. 2015. The monarch butterfly through time and space: the social construction of an icon. BioScience Online Early - doi: 10.1093/biosci/biv045.

Haan, N. L., and D. A. Landis. 2019. The importance of shifting disturbance regimes in monarch butterfly decline and recovery. Frontiers in Ecology and Evolution 7: 8.

Halsch, C. A., A. M. Shapiro, J. H. Thorne, D. P. Waetjen, and M. L. Forister. 2020. A winner in the Anthropocene: changing host plant distribution explains geographical range expansion in the gulf fritillary butterfly. Ecological Entomology 45: 652-662.

Hartzler, R. G. 2010. Reduction in common milkweed (Asclepias syriaca) occurrence in Iowa cropland from 1999 to 2009. Crop Protection 29: 1542-1544.

Howard, E., and A. K. Davis. 2015. Investigating long-term changes in the spring migration of monarch butterflies (Lepidoptera: Nymphalidae) using 18 years of data from Journey North, a citizen science program. Annals of the Entomological Society of America 108: 664-669.

Inamine, H., S. P. Ellner, J. P. Springer, and A. A. Agrawal. 2016. Linking the continental migratory cycle of the monarch butterfly to understand its population decline. Oikos 125: 1081-1091.

Journey North. 2019. Journey North website. https://journeynorth.org/monarchs.

Kinkead, K. E., T. M. Harms, S. J. Dinsmore, P. W. Frese, and K. T. Murphy. 2019. Design implications for surveys to monitor monarch butterfly population trends. Frontiers in Ecology and Evolution 7: 11.

Knight, S. M., D. R. Norris, R. Derbyshire, and D. T. T. Flockhart. 2019. Strategic mowing of roadside milkweeds increases monarch butterfly oviposition. Global Ecology and Conservation 19: 10.

Leone, J. B., D. L. Larson, J. L. Larson, N. Pennarola, and K. Oberhauser. 2019. Adult monarch (Danaus plexippus) abundance is higher in burned sites than in grazed sites. Frontiers in Ecology and Evolution 14 November 2019.

Malcolm, S. B. 2018. Anthropogenic impacts on mortality and population viability of the monarch butterfly, pp. 277-302. In M. R. Berenbaum (ed.), Annual Review of Entomology, Vol 63, vol. 63. Annual Reviews, Palo Alto.

Mawdsley, J. R., T. Simmons, and D. Rubinoff. 2020. Voluntary conservation, not regulation, will be key to monarch butterfly recovery. Wildlife Society Bulletin 2020: 1-5.

Mejía, M. M. M. 1996. Caracterización de las colonias de la mariposa monarcha (Danaus plexippus L.) en la reserva esecial de la biosfera en la estado de Michoacán, Mexico. Tesis licenciatura, Universidad Michoacana de San Nicolás de Hidalgo. 
Oberhauser, K., R. Wiederholt, J. E. Diffendorfer, D. Semmens, L. Ries, W. E. Thogmartin, L. Lopez-Hoffman, and B. Semmens. 2017. A trans-national monarch butterfly population model and implications for regional conservation priorities. Ecological Entomology 42: 51-60.

Pleasants, J. 2017. Milkweed restoration in the Midwest for monarch butterfly recovery: estimates of milkweeds lost, milkweeds remaining and milkweeds that must be added to increase the monarch population. Insect Conservation and Diversity 10: 42-53.

Pleasants, J. M., and K. S. Oberhauser. 2013. Milkweed loss in agricultural fields because of herbicide use: effect on the monarch butterfly population. Insect Conservation and Diversity 6: 135-144.

Pleasants, J. M., E. H. Williams, L. P. Brower, K. S. Oberhauser, and O. R. Taylor. 2015. Letter to the Editor: Conclusion of no decline in summer monarch population not supported. Annals of the Entomological Society of America.

Pleasants, J. M., M. P. Zalucki, K. S. Oberhauser, L. P. Brower, O. R. Taylor, and W. E. Thogmartin. 2017. Interpreting surveys to estimate the size of the monarch butterfly population: Pitfalls and prospects. Plos One 12: 16.

Popkin, G. 2020. What is really killing monarch butterflies?, pp. 61-67, Scientific American.

Project, M. L. M. 2019. Spring 2019 MLMP Updates. An e-Newsletter of the Monarch Larva Monitoring Project. https://monarchjointventure.org/images/uploads/mlmp/MLMP_Spring_2019_ML MP_Newsletter.pdf.

Ries, L., D. J. Taron, and E. Rendon-Salinas. 2015. The disconnect between summer and winter monarch trends for the eastern migratory population: possible links to differing drivers. Annals of the Entomological Society of America 108: 691-699.

Ries, L., E. F. Zipkin, and R. P. Guralnick. 2019. Tracking trends in monarch abundance over the 20th century is currently impossible using museum records. Proceedings of the National Academy of Sciences of the United States of America 116: $13745-13748$.

Saunders, S. P., L. Ries, K. S. Oberhauser, W. E. Thogmartin, and E. F. Zipkin. 2018. Local and cross-seasonal associations of climate and land use with abundance of monarch butterflies Danaus plexippus. Ecography 41: 278-290.

Saunders, S. P., L. Ries, N. Neupane, M. I. Ramirez, E. Garcia-Serrano, E. RendonSalinas, and E. F. Zipkin. 2019. Multiscale seasonal factors drive the size of winter monarch colonies. Proceedings of the National Academy of Sciences of the United States of America 116: 8609-8614.

Schultz, C. B., L. M. Brown, E. Pelton, and E. E. Crone. 2017. Citizen science monitoring demonstrates dramatic declines of monarch butterflies in western North America. Biological Conservation 214: 343-346.

Semmens, B. X., D. J. Semmens, W. E. Thogmartin, R. Wiederholt, L. LopezHoffman, J. E. Diffendorfer, J. M. Pleasants, K. S. Oberhauser, and O. R. Taylor. 2016. Quasi-extinction risk and population targets for the Eastern, migratory population of monarch butterflies (Danaus plexippus). Scientific Reports 6: 7.

Slayback, D. A., L. P. Brower, M. I. Ramírez, and L. S. Fink. 2007. Establishing the presence and absence of overwintering colonies of the monarch butterfly in Mexico by the use of small aircraft. American Entomologist Spring 2007: 28-40. 
Stenoien, C., K. R. Nail, J. M. Zalucki, H. Parry, K. S. Oberhauser, and M. P. Zalucki. 2018. Monarchs in decline: a collateral landscape-level effect of modern agriculture. Insect Science 25: 528-541.

Taylor, O. R., J. M. Pleasants, R. Grundel, S. D. Pecoraro, J. P. Lovett, and A. Ryan. 2020. Evaluating the migration mortality hypothesis using monarch tagging data. Frontiers in Ecology and Evolution 7 Aug, 2020.

Taylor, O. R., J. P. Lovett, D. L. Gibo, E. L. Weiser, W. E. Thogmartin, D. J. Semmens, J. E. Diffendorfer, J. M. Pleasants, S. D. Pecoraro, and R. Grundel. 2019. Is the timing, pace, and success of the monarch migration associated with sun angle? Frontiers in Ecology and the Environment 2019.

Thogmartin, W. E., J. E. Diffendorfer, L. Lopez-Hoffman, K. Oberhauser, J. Pleasants, B. X. Semmens, D. Semmens, O. R. Taylor, and R. Wiederholt. 2017a. Density estimates of monarch butterflies overwintering in central Mexico. Peerj 5: 18.

Thogmartin, W. E., R. Wiederholt, K. Oberhauser, R. G. Drum, J. E. Diffendorfer, S. Altizer, O. R. Taylor, J. Pleasants, D. Semmens, B. Semmens, R. Erickson, K. Libby, and L. Lopez-Hoffman. 2017b. Monarch butterfly population decline in North America: identifying the threatening processes. Royal Society Open Science 4: 16.

USFWS. 2020. United States Fish and Wildlife Service Website - Assessing the status of the monarch butterfly https://www.fws.gov/savethemonarch/SSA.html.

Wagner, D. L. 2020. Insect Declines in the Anthropocene, pp. 457-480. In A. E. Douglas (ed.), Annual Review of Entomology, Vol 65, vol. 65. Annual Reviews, Palo Alto.

Wassenaar, L. I., and K. A. Hobson. 1998. Natal origins of migratory monarch butterflies at wintering colonies in Mexico: new isotopic evidence. Proceedings of the National Acadamy of Sciences 95: 15436-15439.

Wepprich, T. 2019. Monarch butterfly trends are sensitive to unexamined changes in museum collections over time. Proceedings of the National Academy of Sciences of the United States of America 116: 13742-13744.

Wepprich, T., J. R. Adrion, L. Ries, J. Wiedmann, and N. M. Haddad. 2019. Butterfly abundance declines over 20 years of systematic monitoring in Ohio, USA. Plos One 14: 21.

Wimberly, M. C., L. L. Janssen, D. A. Hennessy, M. Luri, N. M. Chowdhury, and H. L. Feng. 2017. Cropland expansion and grassland loss in the eastern Dakotas: New insights from a farm-level survey. Land Use Policy 63: 160-173.

Zaya, D. N., I. S. Pearse, and G. Spyreas. 2017. Long-term trends in Midwestern milkweed abundances and their relevance to monarch butterfly dDeclines. Bioscience 67: 342-355. 